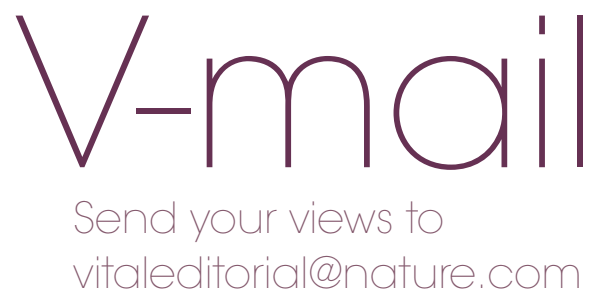

\section{Making learning accessible}

I love reading Vital and would like to introduce our relatively new company to your readers.

You may have heard about us already on Facebook or Twitter or you may have no idea who we are or what we offer.

Ask Learning Academy is a nationwide training company specialising in dentistry. We offer a wide range of services including the NEBDN Dental Nurse Diploma and a variety of ways to gain verifiable continual professional development (CPD).

All of our tutors are qualified dental care professionals (DCPs) with a range of postgraduate qualifications and hold current GDC registration as well as a variety of different teaching qualifications. Between us we have over 100 years' experience in both dentistry and management!

Our aim is to ensure that all of our learners receive the highest standard of professional development enabling them to fully utilise the knowledge gained through our courses in their career. As dentistry changes so rapidly we make certain that all of our material is relevant and up-to-date by continually reviewing the content to match current legislation and professional needs.

Having been on the front line of learning ourselves, we know the importance of making learning accessible and interesting whilst ensuring you can fit it in around your busy working lives.

If you share our passion, why not join us at one of our CPD events? If you are a trainee looking for a course we have the support of expert tutors which will make those big steps into your career easier. www.asklearningacademy.co.uk enquiries@asklearningacademy.co.uk

Louse Hatton

Tutor, Ask Learning Academy

\title{
COMPETITION WINNERS
}

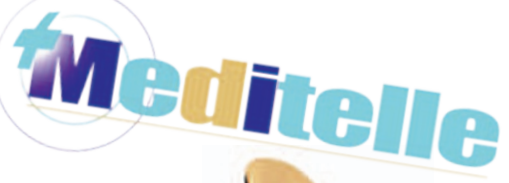

\section{Saddle seat}

In the autumn issue of Vital there was a competition to win an ergonomic saddle seat from Meditelle-Dental. Entrants had to answer this question:

How many free of charge standard vinyl colours are offered by Meditelle-Dental?
A. 9
B. 18
C. 17

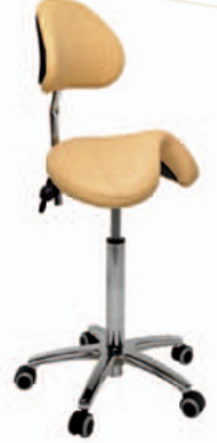

The correct answer was A. 9.

Dawn Miccolis, a practice manager from Oldbury was the lucky winner pulled out of the hat. Dawn can select any stool or chair from Meditelle-Dental's ranges up to the value of $£ 270$ !

\section{Thermae Bath Spa}

Charlotte Butterfield, a dental hygienist from Winchester, won the spa competition featured in the spring 2011 issue of Vital. Charlotte received a pair of four-hour spa session vouchers and a pair of Thermae Trio vouchers entitling Charlotte and a friend to complimentary use of towel, robe and slippers during a visit to Thermae Bath Spa in Bath.

The spa competition asked Vital readers a number of questions about their lives and their opinion on Vital as a magazine. We are pleased to have received some very positive feedback and include some of the

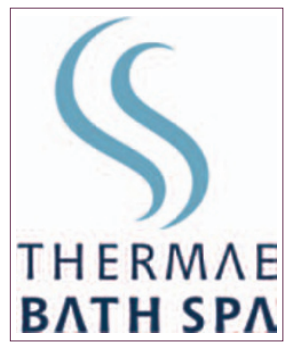
comments here:

'I look forward to receiving my copy of Vital - find it comprehensive, informative and interesting. Well done!' 'It's very enjoyable to read and I look forward to every issue'

'Thank you for a well-rounded magazine'

'I look forward to a good read: jobs out of the way - kettle on'

'Really enjoyable mag which I recommend to others and refer back to'

'A good balance of articles for the whole team'

'Excellent mag - thank you. Topics are vimportant but are easily understood and very factual' 'A very handy resource'

'It's interesting, informative and still does CPD by post (unlike most). It's really convenient for those of us without internet'

'I look forward to seeing it on my doormat'

'Fantastic publication always up to date with information and current trends. I find it really easy to read' 'It's a very enjoyable way to gain CPD hours. I take my copy into our staff room and it gets passed on

from consultants to decontamination assistants. A great read!'

'I read it tonight instead of watching Coronation Street'

\section{CALL FOR LETTERS}

You may have noticed this V-mail page is a little low on letters! Please do get in touch by email or post if you have anything to say about an article in Vital, your job in dentistry, your ambitions, if you have a story to tell or if you would like to pick other readers' brains on something that is on your mind! All correspondence welcome. Ed
Snail mail: Vital Editorial, NPG, 4-6 Crinan Street, London N7 9XW Next issue's star letter writer will win Beverly Hills Formula goodies worth £100. Letters may be edited for space. Opinions expressed do not necessarily reflect those of the editorial team or publishers. 